\title{
Introduction
}

\author{
TIMOTHY G. DINAN
}

It has been known for over a century that abnormalities of glucose metabolism are more common in those suffering from certain forms of mental illness (Kasanin, 1926), but only in the past few years has there been any serious attempt to establish the exact nature of the association. We are now in a situation where a great deal of data and opinions have surfaced in a short space of time. In order to bring this body of data into a single forum to debate its significance and - more importantly to examine how it should influence practice, it was felt appropriate to convene a consensus meeting on diabetes and schizophrenia. The aims of the meeting were to bring a group of interested and informed clinicians and pharmacologists together to present and debate all the currently available data, opinions and practices from around the world that relate to the association between schizophrenia and glucose abnormalities. In order to do this we felt it crucial to involve experts not only in psychiatry but also in diabetology. One of the major roles of the convened group was to give some sort of hierarchical basis to the many types of data that have been published. The prime focus of the group was to agree a consensus statement that would give practising psychiatrists and diabetologists a clear message as to the current state of knowledge, beliefs and potential best practices.

The group identified many areas of debate and disagreement within psychiatry and medicine, and in particular recognised that it is not a universal belief in the UK in 2003 that psychiatrists should indeed be responsible for the physical health of their patients. The aims of the group therefore were to produce a pragmatic and sensible consensus statement, which could be considered for use throughout the UK and Ireland. Most of the recommendations are evidence-based, but in areas where there is a lack of evidence a consensus opinion was formed. Since it is clear that we do not have answers to all of the questions, one of the main conclusions of the group was that large, prospective, longterm studies are urgently required.

Why has a consensus statement not been produced before? The answer to this question is probably that the data simply have not been available until now (Mohan et al, 1999). Dora Kohen points out that the issue has been the subject of much previous debate but such debate has not led to a conclusive outcome. Dixon et al (2000) showed clearly from the Patient Outcomes Research Team database that not only diabetes but very many other physical illnesses are undiagnosed in many of our patients.

\section{UNDIAGNOSED DISEASE}

A vast amount of new data pertaining to glycaemia and schizophrenia has been generated in the past few years. Most of the data have been published in the psychiatric literature, and there is little evidence that physicians and diabetologists have considered this to be an important area for their own research. Yet the diabetic literature is unanimous in the view that throughout the world there are huge numbers of people with undiagnosed diabetes and impaired glucose tolerance (Jonsson, 2002). These patients go undiagnosed primarily because diabetes is often an asymptomatic illness, and even if symptoms are present they are rarely unique and obvious enough to lead to an early diagnosis. This issue is examined in detail by Richard Holt in his review of the epidemiology and the current approach to diagnosis in diabetes mellitus (Holt, 2004, this supplement). He stresses the costly individual, social and economic consequences of the problem.

Within this cohort of people with undiagnosed glucose disorder is a significantly large group of individuals with psychiatric illness. There seems to have been an absence of awareness until recently that schizophrenia (and possibly bipolar disorder as well) could be considered as an independent risk factor for the development of diabetes (Ryan \& Thakore, 2002). A recent $B M J$ series on all aspects of diabetes (epidemiology, diagnosis, management and complications) was notable for its absence of any mention of schizophrenia. Here indeed is a huge potential cohort of people with diabetes, and Bushe $\&$ Holt (2004, this supplement) stress the value of early diagnosis and treatment, which might lead to a reduction in the alltoo-common deaths from cardiovascular events. We know that natural causes and not suicide explain the majority of the excess mortality associated with schizophrenia (Harris \& Barraclough, 1998; Brown et al, 2000). We also know that diabetes is best considered a 'vascular illness', for which most patients routinely receive statins, angiotensin-converting enzyme inhibitors and aspirin in addition to their hypoglycaemic treatments. Furthermore, there appears to be reasonable evidence that diabetes can be prevented if those at greatest risk are targeted early enough and comply with their treatments (Knowler et al, 2002).

\section{HIER ARCHICAL ASSESSMENT OF THE DATA}

One of the most important tasks undertaken by the consensus group was to attempt to classify the many different types of data published and presented on a hierarchical basis. Most data reviewed had been generated from retrospective epidemiological studies which provided incidence and/or prevalence data for diabetes (Cavazzoni $e t$ al, 2004, this supplement). It is important to note that none of these studies gave incidence data relating to impaired glucose tolerance, and none of them specified how many (if any) individuals in each population had been actively screened for abnormal blood glucose levels. Many of these retrospective studies were sponsored by pharmaceutical companies, and most give confusingly different results using essentially the same cohort of patients.

The prospective data examining the relationship between schizophrenia and diabetes began to emerge in 2003, and most of the data currently in the public domain have not yet undergone peer review. This body of data is reviewed by Bushe $\&$ Leonard (2004, this supplement), who 
conclude that the association between schizophrenia, antipsychotic medication and diabetes is largely based on less than optimal retrospective studies. The latter studies are reviewed in the paper by Haddad (2004, this supplement). A few studies have included a placebo group, and through these studies it emerges that we cannot necessarily blame antipsychotic medication when diabetes develops in an individual with schizophrenia. In the prospective studies that included both a placebo group and a requirement to actively and regularly measure blood glucose levels (as in randomised controlled trials performed to US Food and Drug Administration standards), we have learnt that the incidence of newly diagnosed diabetes does not appear to differ greatly between placebo groups and groups in which active drug comparators have been used.

\section{HOW DOES SCHIZOPHRENIA PREDISPOSE TO DIABETES?}

Jogin Thakore reviews his own studies exploring the link between visceral obesity and impaired fasting glycaemia in drugnaïve patients with schizophrenia (Thakore, 2004, this supplement). He suggests that schizophrenia is independently associated with a range of metabolic disturbance. In my own article (Dinan, 2004, this supplement) I link this disturbance to the stress experienced by patients with schizophrenia and the consequent activation of both the hypothalamic-pituitaryadrenal axis and sympatho-adrenal medullary system, while Malcolm Peet examines the association with diet (Peet, 2004, this supplement).

\section{ANSWERING THE DIFFICULT QUESTIONS}

Our consensus meeting considered data in all formats - journals, posters and data

TIMOTHY G. DINAN, MD, PhD, DSc, FRCPsych, Department of Psychiatry, University College, Cork; correspondence: GF Unit, Cork University Hospital,Wilton, Cork, Ireland. E-mail: t.dinan@ucc.ie

available from recent presentations at international congresses. In short, we attempted to have available for review all data that were in the public domain in October 2003. We do not pretend that our group has all the answers, but we hope that at least we might have asked all the questions. What you will find in this supplement is a review of all the data that exist at present to help us answer the most difficult questions relating to diabetes, schizophrenia and antipsychotic medication. The consensus document should best be viewed as a working tool that will allow future best practice to emerge and be tested.

There is little doubt that some psychiatrists feel challenged by non-psychiatric illness and will feel threatened by being asked to screen for a physical illness such as diabetes. However, in their review Gough $\&$ Peveler (2004, this supplement) give pragmatic solutions for intervention in patients with schizophrenia. Overall, we have tried in this supplement to give suggestions, rather than be too prescriptive about the services individual psychiatrists might provide and the roles they might choose to adopt. There may be merit in reconvening the group in the months and years ahead as more data emerge.

\section{REFERENCES}

Brown, S., Inskip, H. \& Barraclough, B. (2000) Causes of the excess mortality of schizophrenia. British Journal of Psychiatry, 177, 212-217.

Bushe, C. \& Holt, R. (2004) Prevalence of diabetes and impaired glucose tolerance in patients with schizophrenia. British Journal of Psychiatry, 184 (suppl. 47), s67-s7l.

Bushe, C. \& Leonard, B. (2004) Association between atypical antipsychotic agents and type 2 diabetes. Review of prospective clinical data. British Journal of Psychiatry, 184 (suppl. 47), s87-s93.
Cavazzoni, P., Mukhopadhyay, N., Carlson, C., et al (2004) Retrospective analysis of risk factors in patients with treatment-emergent diabetes during clinical trials of antipsychotic medications. British Journal of Psychiatry, 184 (suppl. 47), s94-s।0I.

Dinan, T. (2004) Stress and the genesis of diabetes mellitus in schizophrenia. British journal of Psychiatry, $\mathbf{1 8 4}$ (suppl. 47), s72-s75.

Dixon, L., Weiden, P., Delananty, J., et al (2000) Prevalence and correlates of diabetes in national schizophrenia samples. Schizophrenia Bulletin, 26, 903-912.

Gough, S. \& Peveler, R. (2004) Diabetes and its prevention: pragmatic solutions for people with schizophrenia. British Journal of Psychiatry, 184 (suppl. 47), s106-sllI.

Haddad, P. M. (2004) Antipsychotics and diabetes: review of non-prospective data. British Journal of Psychiatry, 184 (suppl. 47), s80-s86.

Harris, E. \& Barraclough, B. (1998) Excess mortality of mental disorder. British Journal of Psychiatry, 173, II-53.

Holt, R. I. G. (2004) Diagnosis, epidemiology and pathogenesis of diabetes mellitus: an update for psychiatrists. British Journal of Psychiatry, 184 (suppl. 47), s55-s63.

Jonsson, B. (2002) Revealing the cost of type II diabetes in Europe. Diabetologia, 45, S5-12.

Kasanin, J. (1926) The blood sugar curve in mental disease. II: The schizophrenic (dementia praecox) groups. Archives of Neurology and Psychiatry, 16, 4I4-4I9.

Knowler, W. C., Barrett Connor, E., Fowler, S. E., et al (2002) Reduction in the incidence of type 2 diabetes with lifestyle intervention or metformin. New England Journal of Medicine, 346, 393-403.

Kohen, D. (2004) Diabetes mellitus and schizophrenia: historical perspective. British Journal of Psychiatry, $\mathbf{1 8 4}$ (suppl. 47), s65-s66.

Mohan, D., Gordon, H., Hindley, N., et al (1999) Schizophrenia and diabetes mellitus. British Journal of Psychiatry, 174, 180-181.

Peet, M. (2004) Diet, diabetes and schizophrenia: review and hypothesis. British Journal of Psychiatry, $\mathbf{1 8 4}$ (suppl. 47), sI02-sI05.

Ryan, M. C. M. \& Thakore, J. H. (2002) Physica consequences of schizophrenia and its treatment: the metabolic syndrome. Life Sciences, 7I, 239-257.

Thakore, J. H. (2004) Metabolic disturbance in firstepisode schizophrenia. British Journal of Psychiatry, 184 (suppl. 47), s76-s79. 